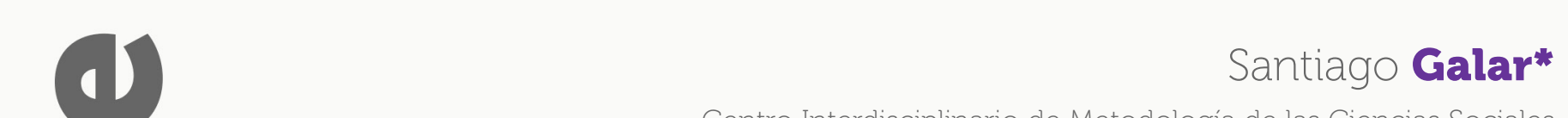

Centro Interdisciplinario de Metodología de las Ciencias Sociales Instituto de Investigación en Humanidades y Ciencias Sociales (FAHCE/CONICET)

Calle 51 e/ 124 y 125 (1925), Ensenada, Buenos Aires, Argentina

santiago_galar@hotmail.com

\title{
"Que la sangre de un policía no seque rápido". \\ Sentidos otorgados a la muerte en la práctica de activistas vinculados a instituciones policiales en Buenos Aires, Argentina
}

\author{
"That a policeman's blood does not dry fast." \\ Sentences granted to death in the practice of \\ activists linked to police institutions in Buenos Aires, \\ Argentina
}

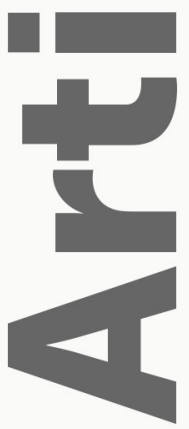

\section{RESUMEN}

La muerte y el riesgo de morir, elementos centrales en las representaciones de los/as policías sobre su profesión, poseen un lugar destacado en las demandas en torno a las cuales se organizan activistas vinculados/as a la institución, en sus modos de presentarse en el espacio público y en el sentido que otorgan a sus prácticas. El presente trabajo propone analizar la práctica de estos/as activistas, específicamente de aquellos asentados/as en la región metropolitana de Buenos Aires, identificando usos sociales y disputas simbólicas que refieren a la muerte de agentes policiales. Con estos fines realizamos entrevistas en profundidad con miembros de organizaciones de familiares de policías, familiares de policías fallecidos movilizados en demanda de justicia y referentes de entidades policiales de perfil sindical. De esta manera, integramos en el análisis discursos y prácticas públicas con dinámicas que los actores sostienen en las burocracias institucionales. Como punto de llegada damos cuenta de diversos sentidos otorgados a la muerte en la práctica de estos actores y formas en que se conjugan con definiciones sobre las condiciones laborales de los/as agentes, el carácter sacrificial de la profesión y el destacado (y ocultado) rol social de la actividad policial, en el marco de un reclamo más general por el reconocimiento de derechos.

Palabras Clave: Policía - Muerte - Heroísmo - Sacrificio - Activismo

\begin{abstract}
Death and the risk of dying, central elements in the representations of the police on their profession, they have a prominent place in the demands around which activists linked to the institution are organized, in the ways of presenting themselves in the public space and in the sense they give to their practices. The present work analyzes the practice of these activists, specifically those who act in the metropolitan region of Buenos Aires, identifying social uses and symbolic disputes that refer to the death of police agents. With this objective, we conducted in-depth interviews with members of organizations of family members of police officers, relatives of deceased police officers who demand justice, and members of trade union police entities. In this way, we analyze together discourses and public practices and dynamics that the actors develop in the institutional bureaucracies. As a point of arrival, we identify meanings given to death in the practice of these actors and ways in which they combines with definitions on the working conditions of the agents. They are also combined with the sacrificial character of the profession and the outstanding (and hidden) social role of police activity, in the context of a more general claim for the recognition of rights
\end{abstract}

Keywords: Police - Death - Heroism - Sacrifice - Activism

* Doctor en Ciencias Sociales (UNLP). Investigador en el Instituto de Investigación en Humanidades y Ciencias Sociales (IdIHCS / UNLP-CONICET). CV: http://independent.academia.edu/SantiagoGalar. 
a posibilidad de matar, de gestionar la vida de terceros, es constitutiva del trabajo policial. En el área comprendida por la ciudad de Buenos Aires y su conurbano, según organismos de derechos humanos, las muertes por el accionar policial se cuentan muerte legalmente a un ciudadano es una de las particularidades que asume el trabajo policial. En este aspecto se monta, para Bittner (2003), la definición misma de la policía como único agente de la sociedad moderna habilitado legal y socialmente para hacer uso de la fuerza. En esta línea se colocan investigaciones realizadas en Argentina acerca del uso de armas de fuego (Lorenz, 2017) y de la expresión de la violencia (Hathazy, 2004; Tiscornia, 2004).

Pero la muerte y la posibilidad de morir también constituyen elementos centrales en las representaciones de los/as policías sobre su profesión. La muerte como horizonte posible de la cotidianeidad laboral se constituye como una marca distintiva de la representación de los miembros de las fuerzas de seguridad (Garriga Zucal, 2017). Bover y Maglia (2018), en su etnografía en escuelas de formación de la Policía Federal Argentina, destacan los modos en los cuales la muerte policial, la heroización de los caídos y las renuncias que los/as policías realizan se inscriben en una semántica institucional que promueve una identificación colectiva. El culto a "los caídos" permite a la institución resignificar la muerte, transformarla en algo positivo: el heroísmo (Galvani 2009, en Galvani y Mouzo, 2014). En este sentido, para Sirimarco (2017), el relato institucional del caído, al prestigiar la tragedia y enmascarar un sistema plagado de ineficiencias, actúa trocando la falla en triunfo. De esta manera, para los/as policías el riesgo de morir se presenta como una experiencia posible, cercana, en ocasiones inminente.

Frente al carácter inexistente -o al menos oculto- de las cifras oficiales, informes construidos a partir de fuentes alternativas dan cuenta de tres tendencias sobre las muertes policiales. En primer lugar, el grueso de las muertes, más del 90\% según las estadísticas del Centro de Estudios Legales y Sociales (CELS), corresponde a policías con actuación en la zona metropolitana. Una segunda tendencia indica que más del $85 \%$ de las muertes ocurre en la zona oeste y sur del conurbano bonaerense, donde vive gran parte de los/as policías que trabajan en la ciudad de Buenos Aires. Un tercer dato es que un alto número de las muertes de policías, alrededor del 75\% de las registradas entre 1996 y 2017, corresponde a policías "fuera de servicio" (es decir, "de franco" o retirados). ${ }^{2}$ Frente a la ausencia de datos oficiales, diversos indicadores dan cuenta que la muerte de policías no es común en términos estadísticos. Sin embargo, a través de placas, fotos y obras monumentales, la muerte posee una gran presencia en los espacios institucionalmente significativos de la policía.

En las ciencias sociales brasileñas, las cuales poseen una tradición pujante en el análisis de procesos ligados a la violencia, la seguridad y la justicia criminal (Kant de Lima et al., 2000), se destacan interesantes aportes vinculados a la salud física y mental de los/as policías, tema inexplorado por la academia argentina. Para Minayo et al. (2011), en línea con lo que afirmamos

1 Según el Centro de Estudios Legales y Sociales fueron al menos 107 particulares los que resultaron muertos en hechos de violencia con participación policial en el Área Metropolitana de Buenos Aires durante 2017. Disponible en <https://www.cels.org.ar/web/letalidad-policial-estadisticas/>. Acceso en 31/10/2018.

2 La serie estadística del CELS, que registra datos entre 1996 y 2017, da cuenta que la mayoría de estas muertes se produjeron en el conurbano de la ciudad de Buenos Aires, más del 85\% desde 2011, por el accionar de policías "fuera de servicio", un 74\% en promedio desde el inicio de la serie. 
anteriormente, el "riesgo" desempeña un papel estructurante de las condiciones laborales, ambientales y relacionales de la profesión policial. Para Oliveira et al. (2010), en un análisis sobre enfermedades físicas y mentales derivadas de las condiciones del trabajo policial en Río de Janeiro, la vida profesional de los/as agentes está permeada por situaciones que generan evidentes cuadros de desequilibrio emocional. ${ }^{3}$ La línea de investigación sostenida por la Fundação Oswaldo Cruz destaca el crecimiento de la victimización fatal y no fatal en policías de Río de Janeiro, siendo la Policía Militar la que presenta mayores tasas de mortalidad (Minayo et al., 2007). ${ }^{4}$ Más allá de las diferencias en el ethos y la dinámica operacional de las diferentes corporaciones policiales, se manifiesta una compartida percepción de vivir en riesgo. Sin embargo, según la investigación desarrollada en Río de Janeiro por Constantino et al. (2013), el riesgo evidencia gradientes diferenciados en relación a la función y al territorio de actuación de los/as policías. Para los/as agentes, por ejemplo, actuar en la capital del estado significa exponerse a un riesgo mayor, presente tanto en el transporte público, en los días de franco y en el ejercicio de tareas profesionales. De esta manera, según estas investigaciones, la posibilidad de la muerte como expresión extrema del riesgo constituye para los/as policías, además de una experiencia vivenciada como posible, un factor que impacta de manera contundente en su salud mental y física.

La muerte es una experiencia presente para los actores que forman parte de la "familia policial", un enunciado mediante el cual, como destaca Calandrón (2014), los actores integran a las familias de los/as miembros de la policía y, simultáneamente, caracterizan a la institución misma como una "gran familia". El objetivo del presente trabajo es analizar prácticas y sentidos vinculados a la muerte que se encuentran presentes en las acciones de miembros de esta familia policial a quienes, por su voluntad de movilizarse recurrentemente en el espacio público en demandas relacionadas con este colectivo profesional, denominamos "activistas". Reparamos específicamente en usos y disputas simbólicas que refieren a la muerte de agentes policiales manifestadas por activistas de la familia policial con actuación en la región metropolitana de Buenos Aires, incluyendo en esta zona tanto a la Ciudad de Buenos Aires y su conurbano como al Gran La Plata, integrado por la capital de la provincia de Buenos Aires, ubicada a unos 50 kilómetros de la capital nacional, y su conurbano.

En relación con las fuerzas policiales con actuación en la zona metropolitana, eje de nuestra indagación, caben algunas consideraciones. Este colectivo incluye a la Policía de la provincia de Buenos Aires (PPBA), la mayor fuerza policial argentina, con un total aproximado de 100 mil agentes y jurisdicción sobre 15 millones de personas. La PPBA cuenta además con cuerpos de policías comunales, creadas en 2004, con funciones en 29 de los 135 municipios provinciales y policías locales, creadas en el año 2014, con actuación en 46 municipios. En la actualidad, desandando la participación otorgada a los ejecutivos municipales, la gestión provincial asumida en 2015 inició un proceso de unificación de estas fuerzas alrededor de la

3 Según esta investigación el 91,7\% de los policías entrevistados se percibía estresado, una parte considerable (el $41,7 \%$ ) afirmó haber actuado impulsivamente, el $88,3 \%$ se sentía emocionalmente cansado, el $62,5 \%$ afirmó en ocasiones actuar agresivamente en el trabajo, y el 20,8\% pensó en el suicidio. Ver Oliveira et al. (2010)

4 Por poner un ejemplo, en 2004 la Policía Militar presentó una mortalidad por violencia 3,3 veces mayor que la sufrida por la población masculina y 6,5 veces mayor que la de la población total de la ciudad (Minayo et al., 2007). 
jefatura de la PPBA. También ejerce funciones en el territorio la Policía Federal Argentina (PFA), dependiente del Gobierno Nacional, la cual cuenta con destacamentos en todas las provincias del país. Hasta fines de 2016 la PFA ejerció también funciones de policía local en la Ciudad Autónoma de Buenos Aires en conjunto con la Policía Metropolitana, creada en 2008. En noviembre de 2016, en el marco de un complejo proceso de traspaso de agentes entre fuerzas, entró en actividad la Policía de la Ciudad, una fusión de la PFA asentada en la Capital y la Policía Metropolitana. El presente análisis, sostenido en un trabajo de campo realizado entre los años 2015 y 2017, indaga sobre sentidos y prácticas de actores vinculados a estas fuerzas atravesadas por estos procesos de cambio.

Realizamos quince entrevistas con miembros de organizaciones de familiares de policías, familiares de policías movilizados/as en demandas de justicia, referentes de entidades policiales de perfil sindical y administradores de fan pages vinculadas a colectivos policiales de la red social Facebook, entre otros/as. Las entrevistas tuvieron lugar durante los años 2016 y 2017, luego de realizar contactos con los actores vía redes sociales. Participamos asimismo de acciones colectivas de protesta producidas en el espacio público, sucedidas entre 2015 y 2017, convocadas por estos actores. Salvo excepciones explícitas, los nombres de activistas, organizaciones y colectivos fueron cambiados para preservar sus identidades.

El artículo da cuenta de sentidos otorgados a la muerte en la práctica de estos actores y formas en que se conjugan con definiciones sobre las condiciones laborales de los/as agentes, el carácter sacrificial de la profesión y el destacado (y ocultado) rol social de la actividad policial. "Que la sangre de un policía no seque rápido" es una demanda extendida que apela a que los/ as agentes fallecidos/as sean mantenidos en la memoria social e institucional. Pero también constituye un reclamo, tanto de los/as familiares de las víctimas como de la más amplia "familia policial", para que el sacrificio y el heroísmo de los/as policías fallecidos/as sean repuestos constantemente e influyan en las disputas y demandas, sociales y burocráticas, promovidas a partir de sus muertes.

\section{Cuando mueren policías}

A la hora de referir a la muerte de policías, en términos generales, los actores mencionan la necesidad de reinscribir el carácter de seres humanos de las víctimas, consecuencia de la falta de reconocimiento a la labor policial por parte del Estado (en manos de "los políticos"), de la institución (en manos de "los jefes") y de la sociedad (o "la gente"). Los actores refieren a esta falta de reconocimiento bajo frases del tipo "un policía no se pone un uniforme para que venga un cualquiera y lo mate", "el policía es un ser humano que tiene los derechos igual que todos" o "por vestir un uniforme el policía no deja de ser humano". Esta reafirmación del carácter humano, por lo tanto valioso, de los/as policías, tanto asesinados/as como en riesgo de morir por las condiciones de trabajo impuestas por la institución, la justicia y la política, implica asimismo una demanda de que sus "derechos humanos" sean respetados. "Siempre hemos escuchado que los derechos humanos son para los demás, uno quiere que entiendan 
que los derechos humanos también tienen que ser para los policías", afirmó la esposa de un policía de la PPBA que integra una organización de perfil sindical.

En este sentido, paradójicamente, las valoraciones expresadas en el accionar público de los/as activistas que son familiares de agentes "caídos" son similares a las sostenidas por familiares de víctimas de violencia letal ejercida por la policía. Concretamente, como en la práctica activista de los/as familiares de víctimas de "gatillo fácil" que analiza Pita (2010), los/ as familiares de agentes asesinados/as se oponen públicamente a la condición de "matables" de sus seres queridos. El hermano de un policía asesinado mientras custodiaba una propiedad policial en 2007 en La Plata en diálogo con la prensa refirió a la PPBA como "el papel higiénico más barato que utilizan los políticos y la justicia". ${ }^{5}$ La oposición a considerar a los/as agentes como descartables no radica en su condición de jóvenes de sectores populares, como en los casos de la violencia policial usualmente nominada bajo el eufemismo "gatillo fácil", sino en su condición de policías. Para referir al poco interés de la sociedad y del Estado por la suerte de estos/as servidores/as públicos/as, los/as activistas suelen utilizar en sus intervenciones la frase "la sangre de policía seca rápido".

Como analizamos en un trabajo previo (Galar, 2016), frente a los crímenes policiales los actores suelen apelar a diversas construcciones narrativas mediante las cuales caracterizan a las víctimas. Una es la imagen de "servidores públicos" con la que refieren al perfil profesional de las víctimas, de policías "con vocación" que hasta el momento del crimen ejercían su labor "con orgullo". Esta narrativa coincide con el más general sentido sacrificial otorgado a la actividad, una profesión que trasciende la relación mercantil al incluir una entrega, un "dar todo de sí", una marcada vocación (Galvani, 2016). Una segunda imagen, particularmente importante para las usinas de sentidos familiares, es la condición de ciudadanos de bien de las víctimas: los policías, por ejemplo, fueron en vida "personas educadas" o "buenos padres". Una tercera construcción es la apelación a las figura del "policía caído en cumplimiento del deber", como se encuadra institucionalmente a los/as policías asesinados/as que, como veremos, cumplen determinadas condiciones. Según Galeano (2011) la figura del "caído" fue central en la construcción de la heroicidad en el ámbito policial. Esta figura, según el autor, se instaló históricamente en la cultura policial como práctica institucional que fomentaba ciertos valores policiales, como discurso emocional que promovía la empatía entre los/as vecinos/as y como mecanismo de canalización de reclamos laborales de los/as subalternos. De hecho, según relevamos en un trabajo anterior (Galar, 2016), en los reclamos policiales actuales los/as participantes apelan a la muerte de agentes como una evidencia indiscutible de las adversas condiciones laborales del colectivo profesional. Esta apelación, sin embargo, es resistida por algunos actores que conforman la arena activista por entender que este uso de la muerte es moralmente reprochable. En esta línea, Marta, familiar de policías de la PPBA que suele movilizarse públicamente, afirmó: "no podés utilizar la muerte de policías para la política... ¿por qué tenemos que darle homenaje a los policías caídos? Vos tenés que luchar para que no caigan".

Se desprenden de las entrevistas dos potentes narrativas mediante las cuales los actores

5 "Azules 14-2-12", YouTube, Buenos Aires, 17/02/2012. Disponible en <https://www.youtube.com/watch?v=bh05ttWPTY>. Acceso en 17/02/2012. 
explican la ocurrencia de crímenes de policías. Una narrativa refiere a la muerte como producto de las malas condiciones de trabajo impuestas por la institución policial y el poder político, condiciones que se agravan al considerar el carácter desbordado de la situación delictiva. Se trata de policías que resultan muertos/as por la exposición al riesgo al cual son sometidos por autoridades que, como afirmamos anteriormente, los/as consideran descartables. Una segunda narrativa señala la saña de los/as delincuentes contra los/as agentes, generalmente expresada en el marco de delitos contra la propiedad. Un porcentaje enorme de los/as policías que fallecen, como afirmamos previamente, lo hace estando "fuera de servicio", tanto al actuar ante la ocurrencia de robos a terceros como al responder a intentos de robos sufridos por sí mismos y sus familias. "A mi hijo lo fusilan por encontrarle la gorra", afirmó durante una entrevista Carlos, padre de un joven suboficial de la PFA muerto en un intento de robo en 2012. Marcela, cuñada de un agente de la PFA asesinado durante un tiroteo entre barrabravas, comentó el caso de un joven que "lo vienen a robar y cuando él se identifica como policía lo masacraron delante de la mujer, con 8 tiros". Más tarde refirió a la historia de "otro chico" a quien delincuentes "lo hicieron bajar [de su auto] y cuando lo identificaron que era policía lo arrodillaron y lo ejecutaron". Esta narrativa centrada en la saña de los/as delincuentes contra la policía se construye a partir de un lenguaje cruel y truculento: a los/as policías los/as "fusilan", los/as "masacran", los/as "ejecutan", lo hacen frente a sus seres queridos, lo hacen a pesar de tener asegurados sus botines.

Los/as delincuentes que matan a policías, en esta narración trasversal a los diferentes casos que conocimos durante el trabajo de campo, obtienen prestigio en sus contextos y respeto por parte de sus pares. Sobre su hijo asesinado en el marco de un robo a su casa, Mónica afirmó durante una entrevista: "él eligió ser policía, servir a la policía, con 31 años nos lo arrebataron de este mundo, por gusto y ganas de asesinar porque era un policía". Los actores dan cuenta de un silogismo imperante según el cual los delincuentes "los matan porque saben que son policías" y "la muerte de un policía les da chapa".6 En definitiva, según los/as activistas de la familia policial, un/a policía muerto/a "es un trofeo para el delincuente". Esta certeza sobre los motivos del accionar de los/as asesinos/as habilita que el accionar de otros actores adquiera el rango de escándalo moral: es obsceno que los organismos de derechos humanos "defiendan delincuentes", que el Estado indemnice familiares de delincuentes muertos por policías o que los/as familiares de los delincuentes involucrados en episodios que derivaron en muertes de policías defiendan a sus hijos/as.

Ahora bien, otra dimensión implicada de manera trasversal en los discursos de los/as activistas es la denuncia por la falta de justicia ante los crímenes y la demanda por una "justicia justa", que es la consecuencia práctica de este sentimiento de impunidad. Según Mónica, en relación a los diversos casos sobre los cuales ella, en tanto familiar de víctima, posee conocimiento: "es muy fácil, acá matan y entran hoy [a la cárcel], si se quedan detenidos, salen y matan otro. Salen delante de ti". En el marco de las actividades derivadas del seguimiento de las causas judiciales de los casos, que demanda una actitud proactiva de los/as familiares, se presenta la necesidad de lograr una condena justa para los/as asesinos de policías. En palabras

6 Con "dar chapa" los actores refieren a ganar prestigio. 
de Marcela, cuñada de un suboficial de la PFA asesinado en La Plata, a quien hicimos referencia más arriba:

En el fallecido, [demandamos] justicia. El tema del blindado, en la Panamericana, fue masacre ${ }^{7} .$. los tipos recibieron cuatro años, tres en libertad y tres con arresto domiciliario. Eso no es justicia. El juicio salió después de un año, que la tuvieron a la mujer dando vuelta en los Tribunales. No es justicia. En ese caso nosotros no sentimos que esté representada la familia policial. ${ }^{8}$

La definición de justicia frente a la muerte de policías pivotea entre definiciones legales y expresiones de deseo asentadas en última instancia en una clara orientación punitivista. Entre las definiciones legales los/as activistas suelen demandar a la justicia la utilización de la figura de la "alevosía" presente en el Código Penal como agravante, en su interpretación, para aquellos que asesinan con ensañamiento, particularmente a funcionarios públicos. ${ }^{9}$ En paralelo a estas demandas de "que se cumpla la ley" circulan otras expresiones que exceden lo contemplado por los marcos legales y que suelen ser presentadas en términos más coloquiales: "que no salgan más de la cárcel" o "que se pudran en la cárcel", suelen ser de las más utilizadas.

\section{La muerte en el sentido de la intervención pública}

Dar cuenta del sentido general otorgado por los actores a su práctica activista, en especial de aquellos/as familiares de "policías caídos", permite avanzar en la caracterización del lugar de la muerte en sus acciones de denuncia y demanda al Estado. Por un lado, identificamos prácticas orientadas hacia la búsqueda de repercusiones para casos concretos. Cintia, cuñada de un agente de la PPBA asesinado en La Plata en 2007, por ejemplo, afirmó en una entrevista: "tampoco queríamos llevar una bandera por todos los policías caídos, nosotros tenemos un objetivo que es esclarecer este hecho". Las acciones de Cintia y su círculo familiar, de esta manera, se orientaron hacia la obtención de justicia por el caso, sin incorporar otras demandas o participar de otros reclamos. Por otro lado, entre los/as activistas se evidencian prácticas que parten de casos concretos, pero incorporan al reclamo demandas más generales.

Durante nuestro trabajo de campo pudimos identificar en la práctica activista tres formas de generalización de demandas. Una primera forma de generalización se conecta con la búsqueda de reparación frente a otras muertes producidas. Constituye un ejemplo el caso de Mónica, madre de un policía de la PFA asesinado en 2012 en un intento de robo ocurrido en la casa de la familia, ubicada en el conurbano bonaerense. Mónica no sólo reclama justicia para su hijo sino que acompaña a otros/as familiares de policías asesinados/as, entre quienes

7 Refiere al asalto a un camión de caudales que trasladaba una importante suma de dinero por la Autopista Panamericana, que bordea a la Ciudad de Buenos Aires. En el asalto murieron dos policías, quienes manejaban los patrulleros que custodiaban al camión.

8 Entrevista a Mónica, familiar de policía asesinado, mayo 2016.

9 En el Artículo 80 el Código Penal se afirma que se impondrá reclusión perpetua "al que matare" con "ensañamiento, alevosía, veneno u otro procedimiento insidioso" (inciso $2^{\circ}$ ) y "a un miembro de las fuerzas de seguridad pública, policiales o penitenciarias, por su función, cargo o condición" (inciso $8^{\circ}$ ). 
comparte el conocimiento jurídico y administrativo acumulado, al tiempo que participa de homenajes, recordatorios y juicios. En sus palabras, según nos comentó en una entrevista, a los/as familiares de policías muertos/as "lo único que podemos hacer es acompañarlos, muchas veces, cuando pasa esto, tal vez no hablar mucho pero sí acompañarlos, guiarlos, lo que no saben".

Una segunda forma de generalización en la intervención activista se orienta a que la muerte, aquella que estimuló el ingreso a la arena activista, no afecte en el futuro a otras familias. Marta, madre de agentes de la PPBA en actividad y referente de un colectivo de familiares de policías, sintetiza este sentido cuando afirma "a mí me mataron a un amigo y no quiero que me maten más a nadie". En este orden de cosas, la primera manifestación pública de Marta constó de una participación en una marcha de víctimas del delito en la cual, para denunciar la desprotección de policías, vistió un chaleco antibalas al cual intervino con la palabra "vencido". ${ }^{10}$ "Mi lucha ahora es por los que están vivos también", aseguró Marta sobre su intervención pública.

Una tercera forma de generalización refiere a activistas cuyos reclamos se originan en muertes pero que posteriormente incorporan demandas más amplias vinculadas a las condiciones de trabajo. Marcela, cuñada de un policía de la PFA asesinado a quien referimos anteriormente, en un encuentro en su casa nos dijo: "nosotros nos movilizamos no sólo por muertos sino por demandas de la familia policial". Según Marcela, "en el caso de una muerte en servicio está bien, vas por la reclusión [perpetua], pero la idea es que la institución cuide al funcionario, vos tenés los chalecos, los horarios, pedimos asistencia psicológica y asistencia letrada...". Estas demandas más amplias del colectivo policial, como recuperamos en un trabajo previo (Galar, 2017), incluyen la necesidad de aumentos salariales, de mejoras en las condiciones de trabajo y de los materiales disponibles para desarrollar la tarea y de apoyo de la institución frente a las situaciones derivadas del "combate al delito". Se trata de demandas generales, vinculadas a las condiciones de trabajo, pero que, desde el punto de vista de los actores, en su incumplimiento y en su sumatoria posibilitan la ocurrencia de muertes.

Cabe destacar que los diversos sentidos otorgados a la muerte en el marco de la intervención pública activista recuperados en este apartado poseen en los hechos cierto dinamismo. En otros términos, el contenido de la demanda de los actores varía a lo largo de sus trayectorias al tiempo que se evidencian ciertas confluencias, dado que, por ejemplo, una misma práctica de reclamo suele incluir actores diversos, con intereses variados.

\section{La disputa por el encuadre administrativo}

Las instituciones policiales clasifican a las muertes de su personal en términos administrativos. Por un lado refieren a muertes ocurridas "en servicio", decesos producidos en horario laboral pero desvinculados de la labor policial. Por otro lado identifican muertes de

10 El deterioro de los chalecos antibalas es un reclamo recurrente entre los/as policías que suelen resaltar que se encuentran "vencidos", lo que disminuye la protección brindada ante disparos de armas de fuego. 
policías "en franco de servicio", en el caso de la PPBA, y "desvinculados de servicio", en el caso de la PFA, agentes que fallecen fuera del horario laboral en hechos desvinculados de la labor policial. Las muertes "por acto de servicio", según la normativa de la PFA, identifican a aquellas producidas en horario laboral en el marco de las actividades de tipo policial. ${ }^{11}$ Finalmente, las instituciones categorizan muertes "en acto de servicio", en el caso de la PPBA, y "en y por acto de servicio", en el caso de la PFA, rótulos mediante los cuales refieren a decesos producidos en "actos de arrojo".

En las fuerzas policiales argentinas, por cierto, rige el denominado "estado policial" que exige a un/a policía serlo las 24 horas del día, sin importar sus horarios de trabajo, e intervenir ante situaciones de carácter delictivo que presencie. La portación permanente de armas de fuego fue obligatoria hasta 1999 para la PFA y hasta 2002 para la PPBA. Sin embargo, como bien documenta para la PPBA Garriga Zucal (2014), los/as policías consideran que el suyo es un trabajo "de tiempo completo" para el cual no pueden prescindir de la portación constante del arma de fuego, la que entienden como una herramienta esencial. Como dimos cuenta más arriba, la mayor parte de las muertes durante actuaciones policiales ocurren cuando al toparse con situaciones delictivas policías "fuera de servicio" hacen uso de sus armas de fuego.

Volviendo a los encuadres administrativos, la PPBA y la PFA clasifican las muertes de su personal mediante encuadres que definen los derechos a los cuales acceden los/as deudos. En caso de tratarse de una muerte "en acto de servicio", además del entierro con honras, la PPBA otorga un ascenso post mortem, un subsidio mensual y un subsidio por única vez de 20 sueldos equivalentes a la jerarquía de Comisario. ${ }^{12}$ Si la muerte es catalogada como "en y por acto de servicio", la PFA dispone para la familia de quien muere una pensión correspondiente a dos jerarquías más de las poseídas al momento del deceso (vía ascenso post mortem) y un seguro de 30 sueldos de Comisario General y Jefe de Policía. Las muertes encuadradas como "en servicio" o "franco de servicio" poseen menos beneficios para los deudos. En caso de una muerte "en servicio" en la PFA, por poner un ejemplo, la familia cobra una pensión correspondiente al $70 \%$ de la jerarquía de quien muere. Estas clasificaciones también son válidas para los casos de heridos/as, con la consiguiente diferenciación de derechos y beneficios.

El deceso en las fuerzas de seguridad, además de la dimensión trascendental y emotiva del registro de la muerte, moviliza disputas políticas, administrativas y de reconocimiento social. En su reflexión sobre los usos sociales de la muerte en policías de la PFA, Maglia (2017) repara en el carácter disputado entre actores institucionales y familiares del encuadre administrativo otorgado a la muerte. Los/as entrevistados/as, de hecho, refieren constantemente a las disputas que vinculan a estos encuadres, particularmente a la búsqueda de reconocimiento del estatus de muerto "en y por acto de servicio" o "en acto de servicio". En sintonía con los emergentes recuperados por Maglia (2017), los/as activistas utilizan la noción de "caído" trascendiendo al encuadre administrativo establecido por la institución, identificando con esta categoría a gran

11 La Ley 16.963 establece que un caído en horario laboral murió "como consecuencia del cumplimiento de sus deberes esenciales de defender contras las vías de hecho, o en actos de arrojo, la propiedad, la libertad y la vida de las personas; mantener el orden público, preservar la seguridad pública y prevenir y reprimir la acción delictiva" (Art. 1).

12 Ley provincial 13.985, Disponible en <http://www.gob.gba.gov.ar/legislacion/legislacion/l-13985.html>. Acceso en $31 / 10 / 2018$. 
parte de los/as policías muertos/as.

Betania, una oficial responsable del área de Servicios Sociales de la PPBA, durante una entrevista ilustró con un ejemplo la posibilidad de que a partir de la voluntad de las autoridades se produzcan desplazamientos de estos encuadres:

Por ejemplo el hecho del matrimonio de Matanza que mataron ${ }^{13}$, ellos estaban "franco de servicio", pero lo encuadraron en "acto de servicio" porque ellos se tirotearon con los delincuentes para que no les robaran en la puerta de sus casas. Esa es la potestad del Ministro y del Jefe de Policía, obviamente con un grupo de asesores en la parte legal que dicen qué correspondería. Ellos consideraron, dada la gravedad y cómo se dieron los hechos, porque vos evalúas todo, hay una criatura de tres años de por medio que se quedó sin papá y sin mamá... ${ }^{14}$

El encuadre es un acto administrativo interno realizado en consonancia con la causa judicial de cada caso. Sin embargo, frente a la aparente claridad de los criterios para su diferenciación, los encuadres evidencian cierta plasticidad que se relaciona con las características de determinados hechos que derivan en muertes.

Esta plasticidad, según los actores, es en ocasiones utilizada por la institución para desligarse de las responsabilidades que posee con el personal y sus familias. Martín, agente retirado de la PFA por una discapacidad permanente producto de heridas recibidas en un enfrentamiento, afirmó con cierto sarcasmo que el criterio para realizar los encuadres "es clarísimo" pero "lo que no es claro son los que te juzgan".

Yo tengo el caso, que salía del adicional en el Elefante Blanco, ${ }^{15}$ salía con la moto, tres tipos le afanan, éste tres días antes los había arrestado a los tres. Cuando le sacan el casco le entran a tirar. Le pegaron dos, uno le tocó el nervio ciático. El hiere a uno y se escapan. A los tres días los agarraron a todos, los sentenciaron 17 años por tentativa de homicidio críminis causa, lo quisiste matar para ocultar el delito, porque se comprobó que lo conocían. [En] ese sumario le ponen "desvinculado del servicio" porque dicen que eso le podría haber pasado a cualquier persona, pero no, si vos ibas y te sacabas el casco no te iban a querer matar. Es un claro "en y por acto de servicio". Es la propia policía la que lo define. ${ }^{16}$

En este tipo de ejemplos la institución parece desentenderse de su responsabilidad ante personas heridas cuyos derechos son urgentes y sus reclamos razonables. Para Martín "el peor enemigo" de los/as policías "es la propia institución", en particular Asuntos Internos, una división compuesta por "tipos de carrera que en su vida estuvieron en la calle y no saben cómo

13 Refiere a una pareja de policías de la PPBA, personal de Patrullas de la Departamental de La Matanza, cuyos integrantes fueron asesinados luego de tirotearse con delincuentes que intentaban robarles su automóvil en la localidad de Rafael Castillo, en septiembre de 2015.

14 Entrevista realizada por el autor a Betania, oficial de la PPBA, el 15/08/2016, en La Plata, Buenos Aires, Argentina.

15 El Elefante Blanco es un edificio ubicado en la Ciudad de Buenos Aires, se trata de una estructura abandonada cuyo destino era el ser el hospital más grande de Latinoamérica. El nombre Elefante se debe a su gran tamaño, doce pisos con decenas de salas cada uno.

16 Entrevista realizada por el autor a Martín, agente retirado de la PFA, el 08/09/2016, en la Ciudad Autónoma de Buenos Aires, Argentina. 
son las cosas". En los casos relatados por los/as entrevistados/as el enemigo viste diferentes ropajes, son los abogados que benefician al ministerio ocultando información a los/as familiares y las autoridades políticas que se presentan en los velorios para después "desaparecer". El enemigo es, en el caso de los/as heridos/as, la Junta Médica que "los boludea"17 cuando pese a que la gravedad de las heridas es obvia no justifica el retiro del personal. En palabras de uno de los heridos entrevistados: "han venido chicos con las piernas cortadas y capaz que te boludeaban cinco años una junta médica". De esta manera, en la disputa por el encuadre de agentes muertos/as y heridos/as se evidencian tensiones que, pese a la mirada monolítica aun presente en sectores académicos y políticos, atraviesan a una institución compleja que, como dio cuenta en su estudio sobre la PFA Galvani (2016), colaboran a configurar la identidad policial. En el episodio relatado por Martín, concretamente, se cruzan tensiones entre policías "de calle" y "administrativos", entre "suboficiales" y "oficiales", entre "la tropa" y los "jefes".

Mónica, madre de un cabo de la PFA asesinado en 2012 a quien mencionamos más arriba, refiere al carácter discutido del encuadre otorgado por la institución al episodio en el cual murió su hijo. En su relato, los representantes de la institución dijeron que por haber ocurrido el episodio fuera de la jurisdicción de la PFA, en un robo en la casa familiar ubicada en la provincia de Buenos Aires, no correspondía el encuadre "en y por acto de servicio".

Entonces le dije "mi hijo era policía no dos horas ni cuatro, era 365 días del año y hace 13 años que mi hijo sirve a la institución y a la sociedad", quiere decir que él defendió su casa, violaron los derechos de la vida de él, de toda mi familia. Y ella me sale con una contestación así. Entonces ahí yo empecé a decir "cómo puede ser". ${ }^{18}$

Mónica aclara que su intención, antes que proponerse acceder a los beneficios económicos derivados del encuadre, era promover la investigación judicial por el caso. Un año después del crimen, durante 2013, la PFA reconoció a la muerte de su hijo como "en y por acto de servicio". Fue, según Mónica, "después de haber peleado, paralelo a buscar justicia, buscar que se le reconozcan los derechos de mi hijo para su hijo", su nieto.

Más allá de la claridad aparente de los encuadres disponibles por la normativa se producen entre los actores tensiones y disputas, lo que evidencia el carácter discutido de estos estados. Se juega un valor simbólico, la posibilidad de los/as hijos/as de estudiar, de motorizar la causa judicial, de dar cuenta del acto de entrega del policía "caído".

\section{El problema del desamparo}

Los/as familiares de los/as policías "caídos" quedan, según los actores, "desamparados por la institución", "sin contención", "solos". "A nosotros nos toca cuando matan al hermano de mi marido, pensando que la institución te respalda y nos encontramos con un vacío enorme",

17 Con "boludear" los actores refieren a acciones realizadas para perder el tiempo.

18 Entrevista realizada por el autor a Mónica, familiar de policía asesinado, el 17/08/2016, en la Ciudad Autónoma de Buenos Aires, Argentina. 
denunció Marcela al recordar su caso. Esta falta de contención por parte de la institución, al tiempo que empuja a la acción con miras a lograr justicia y acceder a derechos, constituye un momento para la solidaridad de la familia policial. Carlos, padre de un policía asesinado de la PFA, contó que ante la falta de apoyo de la institución fue una organización de policías la que pagó el cajón y el sepelio. La sensibilidad de la familia policial, en particular de los/ as compañeros/as de los/as policías asesinados/as, aparece en oposición a la frialdad de la institución. "Aparte de sus compañeros no vino nadie más a preguntarnos en qué situación estamos", resumió Marcela. Por lo demás, este estado de desprotección también afecta a los/ as policías que resultan gravemente heridos y sus familiares.

El reclamo por la falta de acompañamiento incluye la ausencia de autoridades políticas e institucionales en las honras fúnebres, particularmente en las correspondientes a policías muertos "en servicio". Luis, policía retirado de la PPBA por las heridas recibidas en un enfrentamiento, indignado por la ausencia de los jefes de la PPBA en un velatorio de un policía asesinado en Mar del Plata, ubicó decenas de cruces en la fachada del edificio en el cual se alojaban las autoridades de la institución. Días después Luis se acercó al acto de egreso de aspirantes a la PPBA y, frente a las cámaras de televisión, increpó a los gritos al ministro por su ausencia en el velorio. ${ }^{19}$ "No les costaba nada, es algo ético", sentenció durante la entrevista. Sin embargo, incluso en caso de participar de las honras fúnebres, este acompañamiento de las autoridades es considerado limitado o simbólico. Según Alberto, referente de una organización de policías, "en ese momento del velatorio, desgraciadamente cuando un compañero cae, va el ministerio, vienen los abogados, pero después se olvidaron la familia". Conociendo esta dinámica, Alberto dice acercarse a los/as familiares una vez que pasó el ceremonial, "porque es ahí cuando la gente queda abandonada".

El abandono estatal a la familia del policía "caído" tiene diversas caras. Una de ellas es la presión sobre los/as familiares para que realicen los trámites para acceder a los derechos derivados de la muerte de su ser querido. "La familia que queda tiene que dar vueltas", afirmó sobre los engorrosos trámites requeridos por la institución Alberto, referente de un colectivo de policías. Los/as familiares atraviesan circuitos burocráticos en un contexto de poca información que, en algunos casos, es descrito como de "desprecio" por personas que se viven momentos dramáticos. Pablo, representante de un colectivo de heridos de la PPBA, apela al caso de la madre de una joven agente asesinada:

Te pongo un ejemplo, la señora Josefa es la mamá de la teniente Gómez, le matan a la hija, no tenía fuerza para levantarse, vino a la oficina de acá y le dijeron que no le correspondía nada. Es la Oficina de Heridos, que es una Dirección. Son organismos con gente y presupuesto, y están para asistir al personal de heridos. Dijeron que no. [...] Le pedían resoluciones, vive en Adrogué, hora y media de viaje, yendo de un lado a otro a buscar cosas. Asistila. ${ }^{20}$

19 Episodio disponible en <https://www.youtube.com/watch? $v=3$ AqRnbpbpP4>. Acceso em 31/10/2017.

20 Entrevista realizada por el autor a Pablo, referente de colectivo de policías heridos, el 29/10/2016, en La Plata, Buenos Aires, Argentina. 
Este incumplimiento en el deber de asistencia constituye una clara referencia al abandono por parte de los/as entrevistados/as. Otra cara del abandono, según nuestra interpretación, es la apatía de la justicia. Mónica, madre de un cabo de la PFA asesinado a quien referimos más arriba, habla de "la lucha" que implica buscar justicia: "hemos tenido que ser prácticamente abogados para llevar las pruebas a la fiscalía, porque la parte judicial es una desidia total".

Los/as agentes y familiares activistas, frente al abandono imperante, acompañan a los/ as nuevos/as afectados/as, principalmente mediante el traspaso del conocimiento acumulado sobre cómo actuar ante este tipo de situaciones. Dora, esposa de un policía herido de la PPBA, destacó que son las mujeres, particularmente "las viudas", aquellas que "van aprendiendo sobre la marcha las cosas" y, luego, se aconsejan con miras a evitar ser engañadas por la institución. Según Martín, policía herido de la PFA, el "desconocimiento" constituye una variable central en el problema del "desamparo". En sus palabras:

A vos te pasa algo, quedás a la buena de dios, eso por desconocimiento. Duele decirlo, pero los policías nunca hablamos de qué pasa si nos matan, vos no se lo decís a la familia, nadie piensa en morir, es como que es un poco yeta ${ }^{21}$. Entonces nadie habla. A vos el día de mañana te pasa algo, tu familia no sabe nada. Más si no vienen de la policía. Y el Estado nadie viene y te dice, o hay una división que dice 'a su marido le pasó esto, a usted le corresponde esto, esto y esto.'.22

En esta línea, Alberto, referente de otro grupo de policías federales, lamentó reconocer "nosotros mismos estuvimos en un momento cerrado con la misma familia", por lo que cuando muere un efectivo "la familia no sabe dónde está parada". Así, mediante el ejercicio de la autocrítica, estos activistas plantean que junto a la falta de compromiso de la institución para con sus miembros interviene un desconocimiento por parte de los/as propios/as interesados/ as sobre sus derechos.

El desamparo institucional y el desconocimiento sobre los derechos, cuando se incorpora un volumen considerable de dinero en forma de subsidios, es un terreno fértil para la emergencia de actores interesados en obtener beneficios. Entre estos actores se destacan los/as abogados/as, también denominados "cuervos" para destacar su carácter de carroñeros, que intervienen negativamente en dos tipos de situaciones. Por un lado, frente a la muerte de policías los/as abogados/as trabajan en la gestión de pensiones, subsidios e indemnizaciones. Un policía herido nos comentó en este sentido: "están las viudas que no tienen ni idea de lo que es una indemnización, los abogados las cagan, se venden". Frente a la muerte de policías, por otro lado, los/as abogados/as ofrecen servicios para el litigio penal que son negados por la institución. En este sentido, los actores se quejan de la falta de abogados/as para llevar adelante las causas en los tribunales, como Marta, quien nos comentó que "cuando te pasa esto [una muerte] nosotros los familiares no tenemos abogados que te defiendan". La opción

21 Con "yeta" se refiere a mala suerte.

22 Entrevista realizada por el autor a Martín, herido de la PFA, el 25/08/2016, en la Ciudad Autónoma de Buenos Aires, Argentina. 
frente a las limitaciones de la defensa provista por la institución es el endeudamiento. "Tenés que pagar, y cobra muchísima plata, todos los padres quedan tirados, venden la casa, el auto", describe Marta. Este endeudamiento, cabe destacar, se produce en el marco más general de una administración que, como dimos cuenta en otro trabajo (Calandrón y Galar, 2017), suele basarse en ciclos de consumo desproporcionado que derivan en economías domésticas desequilibradas y fuertemente endeudadas. Apelar a un abogado particular, para los/as entrevistados/as, puede llevar a que las familias "se queden sin nada".

\section{Reflexiones finales}

Analizamos prácticas y sentidos vinculados a la muerte que se encuentran presentes en las acciones de miembros de la familia policial, particularmente en aquellos/as que identificamos como "activistas", con actuación en la zona metropolitana de Buenos Aires. Dimos cuenta a lo largo del trabajo de diversos sentidos otorgados a la muerte en la práctica de estos actores y formas en que se conjugan con definiciones sobre las condiciones laborales de los/as agentes, el carácter sacrificial de la profesión y el destacado rol social de la actividad policial, en el marco de un reclamo más general por el reconocimiento de derechos.

Referimos en primer lugar a ciertos sentidos expresados por los actores ante la muerte de policías. Identificamos, por ejemplo, la demanda por reinscribir el carácter de seres humanos en los/as policías en tanto, producto de las malas condiciones laborales, la "saña" expresada por los/as delincuentes y la falta de reconocimiento social a su entrega cotidiana, los/as agentes aparecen como seres "desechables". Emerge entre los/as activistas la demanda por el respeto a los derechos más básicos de los/as agentes, la necesidad de reconocimiento a la labor de estos "servidores públicos", el reclamo de "justicia justa" frente a la ocurrencia de asesinatos. Se trata, en definitiva, de sentidos diversos que aparecen sintetizados en la consigna "que la sangre de policía no seque rápido".

En segundo lugar dimos cuenta del sentido general otorgado por los actores a su práctica activista, en especial de aquellos/as familiares de "policías caídos", en relación con el lugar de la muerte en sus acciones públicas. Identificamos, por un lado, prácticas orientadas hacia la búsqueda de repercusiones para casos concretos y, por otro lado, prácticas que si bien parten de casos concretos incorporan paulatinamente demandas más generales. Se trata, por lo demás, de diferencias analíticas en tanto las construcciones que sostienen las prácticas de los/as activistas de la familia policial poseen en los hechos cierto dinamismo.

Seguidamente, en tercer lugar, referimos a procesos administrativos a través de los cuales las instituciones policiales clasifican a las muertes de su personal. Se trata de encuadres administrativos, supuestamente claros, que repercuten directamente en los derechos a los cuales accederán los deudos. Sin embargo, los actores dan cuenta de tensiones y disputas vinculadas a estos procesos de encuadre. Los/as familiares, concretamente, denuncian el desconocimiento de la institución a los "actos de arrojo" de sus "caídos" así como el posterior desconocimiento de los derechos de las familias que, por la muerte de su ser querido, "quedan destruidas". 
El deceso en las fuerzas de seguridad, además de la dimensión trascendental y emotiva del registro de la muerte, moviliza disputas políticas, administrativas y de reconocimiento social.

En cuarto lugar, finalmente, referimos al abandono por parte de la institución a los/as familiares de los/as policías "caídos" denunciado por los actores. El abandono institucional a la familia del policía "caído" posee diversas expresiones, entre ellas la ausencia de autoridades en las honras fúnebres, la presión sobre los/as familiares para que realicen engorrosos trámites para acceder a subsidios y pensiones, la apatía de la justicia y la exposición a abogados/as que pretenden abusar de la situación. Frente al desamparo institucional emerge la solidaridad "familiar", en tanto son los/as compañeros/as quienes se presentan como sensibles a las necesidades de los deudos y los activistas quienes acompañan a los/as afectados/as en el proceso de enfrentar la muerte de sus familiares.

En quinto lugar, damos cuenta que en las disputas por los encuadres administrativos que categorizan a las muertes, en las denuncias por la falta de reconocimiento por parte de la institución a las familias de los/as fallecidos/as y en la impugnación de las condiciones laborales de los/as policías subyace, desde nuestro punto de vista, la idea de sacrificio. El sacrificio se manifiesta constantemente en las prácticas y significados expresados por los actores. Como dimos cuenta a lo largo de este artículo, el riesgo vinculado a la profesión, cuya materialización extrema sería la muerte, es una constante en la significación de la tarea policial. La ocurrencia de muertes, aunque inusual en el contexto local, permite materializar la idea de sacrificio, dotarla de concreción, reforzando los sentidos (y los riesgos) a los cuales se asocia la tarea policial.

De esta manera, nuestro planteo avanza en dos direcciones generales. Por un lado, avanza en la visibilización de los/as activistas vinculados a la "familia policial". Se trata de una invitación a considerar a estos actores, usualmente relegados por el análisis académico, en el más amplio escenario de la conflictividad de la Argentina del siglo XXI. Por otro lado, avanza en la identificación y análisis de disputas en el marco de la institución policial, particularmente aquellas que tienen como eje a las muertes de agentes policiales. Se trata en este caso de deconstruir una mirada instalada, cada vez más discutida en el ámbito académico, que entiende a la policía como una institución cerrada, monolítica y homogénea.

\section{Bibliografía}

BITTNER, Egon. Aspectos do trabalho policial. São Paulo: EDUSP, 2003. 217p.

BOVER, Tomás y MAGLIA, Elea. ¿Están preparados para morir? La muerte en la profesión policial. Avá. Misiones/AR, n. 30, p. 159-180, 2018. Disponible en <http://www.ava.unam.edu. ar/images/30/pdf/n30a08.pdf>. Acceso en 31/10/2018.

CALANDRÓN Sabrina y GALAR Santiago. Dinero, trabajos alternativos y consumos en la vida cotidiana de policías de la Provincia de Buenos Aires. Prácticas de Oficio. Online, v. 2, n. 20, p. 14-23, 2017. Disponible en <http://ides.org.ar/wp-content/uploads/2012/04/2-CALANDRON-YGALAR.pdf >. Acceso en 31/10/2018.

CALANDRÓN, Sabrina. Género y sexualidad en la Policía Bonaerense. Buenos Aires: UNSAM 
Edita, 2014. 204p.

CONSTANTINO, Patricia, RIBEIRO, Adalgisa Peixoto y CORREIA, Bruna Soares Chaves. Percepção do risco entre policiais civis de diferentes territórios do Estado do Rio de Janeiro. Ciência \& Saúde Coletiva. Rio de Janeiro, v. 18, n. 3, p. 645-655, 2013.

OLIVEIRA, Katya Luciane de y SANTOS, Luana Minharo dos. Percepção da saúde mental em policiais militares da força tática e de rua. Sociologias. Porto Alegre, v. 12, n. 25, p. 224-250, 2010.

GALAR, Santiago. Dimensiones del activismo policial. Un análisis de prácticas sostenidas ante la masacre policial ocurrida en La Plata en 2007. Question. La Plata, v. 1, n. 51, p.188-204, 2016. Disponible en <https://perio.unlp.edu.ar/ojs/index.php/question/article/view/3353>. Acceso en 31/10/2018.

GALAR, Santiago. Policías en acción. Hacia una caracterización de la red de activistas vinculados a la institución policial en la región metropolitana. Argumentos: Revista de Crítica Social. Buenos Aires, n. 19, p. 43-63, 2017. Disponible en <http://publicaciones.sociales.uba.ar/index.php/ argumentos/article/view/2547>. Acceso en 31/10/2018.

GALEANO, Diego. Caídos en cumplimiento del deber. Notas sobre la construcción del heroísmo policial. En: KAMINSKY, Gregorio y GALEANO, Diego (Coords.). Mirada (de) uniforme: Historia y crítica de la razón policial. Buenos Aires: Teseo, p.185-222, 2011.

GALVANI, Mariana y MOUZO, Karina. Locos y mártires. Un análisis comparativo entre dos fuerzas de seguridad argentinas. En: FREDERIC, Sabina; GALVANI, Mariana; GARRIGA ZUCAL, José y RENOLDI, Brigida. (Eds.). De Armas Llevar: estudios socio antropológicos de los quehaceres de policías y de las fuerzas de seguridad. La Plata: Publicaciones de Periodismo, p. 355-378, 2014.

GALVANI, Mariana. Cómo se construye un policía: La Federal desde adentro. Buenos Aires: Siglo XXI Editores, 2016. 237p.

GARRIGA ZUCAL, José. Por el pancho y la coca. Apuntes sobre las representaciones del trabajo entre los policías de la provincia de Buenos Aires". Papeles de Trabajo. San Martín, v. 8, n. 13, p. 34-53, 2014.

GARRIGA ZUCAL, José. Sobre el sacrificio, el heroísmo y la violencia: Aportes para comprender las lógicas de acción en las fuerzas de seguridad. Buenos Aires: Editorial Octubre, 2017. 219p.

HATHAZY, Paul. Cosmologías del desorden: el sacrificio de los agentes antidisturbios y el sentido de su violencia. In: ACTAS DEL VII CONGRESSO ARGENTINO DE ANTROPOLOGÍA SOCIAL, Córdoba, Museo de Antropología, 2004. [Cd-rom].

KANT DE LIMA, Roberto, MISSE, Michel y MENDES DE MIRANDA, Ana Paula. Violência, Criminalidade, Segurança Pública e Justiça Criminal no Brasil: Uma Bibliografia. Revista Brasileira de Informação Bibliográfica em Ciências Sociais. Online, n. 50, p. 45-123, 2000.

LORENZ, Mariana. El 'verdadero' trabajo policial. Representaciones de los funcionarios de la Policía Federal Argentina acerca de su quehacer profesional. Papeles de Trabajo. San Martín, v. 11, n. 19, p. 99-120, 2017. Disponible en <http://www.unsam.edu.ar/ojs/index.php/papdetrab/ article/view/140/265>. Acceso en 31/10/2018.

MAGLIA, Elea. Morir para servir: Representaciones sobre la muerte y construcción de identidad 
en la Policía Federal Argentina. Tesis (Maestría en Sociología del Poder), Programa de posgrado en Antropología Social, Universidad Nacional de San Martín, San Martín, 2017. 158 páginas.

MINAYO, María Cecilia de Souza, ASSIS, Simone Gonçalves de y OLIVEIRA, Raquel Vasconcellos Carvalhaes de. Impacto das atividades profissionais na saúde física e mental dos policiais civis e militares do Rio de Janeiro (RJ, Brasil). Ciência \& Saúde Coletiva, v.16, n. 4, p. 2199-2209, 2011.

MINAYO, María Cecilia de Souza, SOUZA, Edilsina Ramos y CONSTANTINO Patricia. Riscos percebidos e vitimização de policiais civis e militares na (in)segurança pública. Cadernos de Saúde Pública. Rio de Janeiro, v. 23, n. 11, p. 2767-2779, 2007.

PITA, María Victoria. Formas de morir y formas de vivir: El activismo contra la violencia policial. Buenos Aires: Editores del Puerto, 2010. 242p.

SIRIMARCO, Mariana. El relato del "caído en cumplimiento del deber": cuando la falla se vuelve gloria". GARRIGA ZUCAL José. (Comp.). Sobre el sacrificio, el heroísmo y la violencia: Aportes para comprender las lógicas de acción en las fuerzas de seguridad. Buenos Aires: Editorial Octubre, p. 43-66, 2017.

TISCORNIA, Sofía. Burocracias y violencia: Estudios de antropología jurídica. Buenos Aires: Antropofagia, 2004. 465p.

Recibido en: 1 de diciembre de 2018

Aprobado en: 19 de diciembre de 2019 